\title{
Synthesis of Colloidal Ruthenium Nanocatalyst by Chemical Reduction Method
}

\author{
R. G. Patharkar, S. U. Nandanwar, and M. Chakraborty \\ Department of Chemical Engineering, Sardar Vallabhbhai National Institute of Technology, Gujarat, Surat-395007, India \\ Correspondence should be addressed to M. Chakraborty; mch@ched.svnit.ac.in
}

Received 27 February 2012; Revised 12 May 2012; Accepted 25 May 2012

Academic Editor: Danielle Ballivet-Tkatchenko

Copyright (C) 2013 R. G. Patharkar et al. This is an open access article distributed under the Creative Commons Attribution License, which permits unrestricted use, distribution, and reproduction in any medium, provided the original work is properly cited.

Colloidal ruthenium nanoparticles were prepared by chemical reduction of ruthenium trichloride $\left(\mathrm{RuCl}_{3}\right)$ using sodium borohydrate $\left(\mathrm{NaBH}_{4}\right)$ as reducing agent and sodium dodecyl sulfate (SDS) as a stabilizer. Size and size distribution of synthesized colloidal Ru nanoparticles were studied by varying different parameters such as molar ratio (MR) of SDS/RuCl $3, \mathrm{NaBH}_{4} / \mathrm{RuCl}_{3}$, effects of different stabilizers, and reducing agents. Prepared nanoparticles were characterized by transmission electron microscope (TEM) and dynamic light scattering (DLS). Stability of colloidal nanoparticles was detected by Turbiscan. Stable Ru nanoparticles were dispersed on $\gamma-\mathrm{Al}_{2} \mathrm{O}_{3}$ to prepare $\mathrm{Ru} / \gamma-\mathrm{Al}_{2} \mathrm{O}_{3}$ catalyst. This catalyst was characterized by X-ray Diffraction (XRD) and transmission electron microscope (TEM).

\section{Introduction}

Metal nanoparticles have of great fundamental and practical interest due to their unique physical properties, chemical reactivity, and potential applications in electronics, catalysis, and biochemistry [1, 2]. Nanoparticles of many metals, such as gold, platinum, palladium, cobalt, silver [3], and rhodium [4], have been synthesized by different experimental techniques. However, the synthesis of ruthenium $(\mathrm{Ru})$ nanoclusters is scarcely reported, despite the important technological role of ruthenium [5] as a catalyst and redox processes [6]. It also serves as electrocatalyst in the electrooxidation of methanol and $\mathrm{CO}$, the core reaction that occurs in direct methanol fuel cells [7]. The catalytic activities of the $\mathrm{Ru}$ nanoparticles have been tested for partial oxidation of methane shows high activity and high CO selectivity [8].

Among the various techniques to obtain nanosized metal particles, the wet chemical method is probably the most popular due to its simplicity, low cost, and ability to produce large quantity. Chemical reduction of metal salts using various reducing agents in the presence of protecting agent is preferred due to the advantage of controllable size and shape of the particles [8]. Chemical reduction method have been carried out in the presence of a stabilizer such as linear polymers, ligands, surfactants, or heterogeneous supports, which prevents the nanoparticles from aggregating, allowing at the same time their isolation [9]. In order to synthesize uniformly distributed nanocatalyst, stability of the colloidal nanoparticles and the homogeneous dispersion over the support play the most important role.

In view of above literature, attempts had been made to synthesize uniformly distributed stable ruthenium by chemical reduction method using SDS as stabilizing agent. Different parameters which affect particle size and size distribution such as molar ratio (MR) of $\mathrm{SDS} / \mathrm{RuCl}_{3}, \mathrm{NaBH}_{4} / \mathrm{RuCl}_{3}$, effects of different stabilizers, and reducing agents were studied systematically. Turbiscan had been used to monitor stabilized $\mathrm{Ru}$ nanoparticles and dispersions in the kinetic studies of their stability. Stable colloidal ruthenium nanoparticles were dispersed on $\gamma-\mathrm{Al}_{2} \mathrm{O}_{3}$ by mechanical stirring and characterized using XRD and TEM.

\section{Experimental}

2.1. Materials. Ruthenium trichloride $\left(\mathrm{RuCl}_{3} \cdot n \mathrm{H}_{2} \mathrm{O}\right)$, sodium borohydrate $\left(\mathrm{NaBH}_{4}, 95 \%\right)$, hydrazine hydrate $(80 \%)$, sodium dodecyl sulphate (SDS), and cetyltrimethylammonium bromide (CTAB) were purchased from Finar Chemicals, 


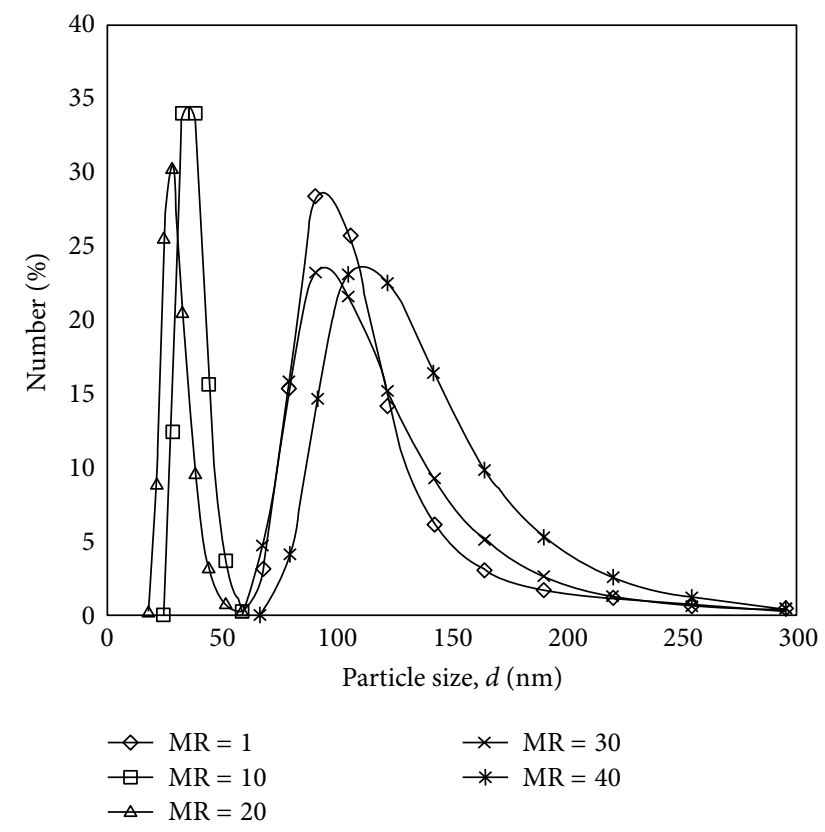

FIGURE 1: Study of effect of SDS/ $\mathrm{RuCl}_{3} \mathrm{MR}$ on particle size using particle-size analyser.

India. Poly ( $N$-vinyl-2-pyrrolidone) (PVP, average molecular weight 40,000) and Aerosol OT (AOT) were purchased from Heny Fine Chemicals, India. Gamma alumina powder of 98\% purity was purchased from National Chemicals, India. Distilled water of $\mathrm{pH} 5.9 \pm 0.2$, conductivity $1.0 \mu \mathrm{S} / \mathrm{cm}$ (Millipore, Elix, India) was used throughout the experiments for preparing the aqueous solutions.

2.2. Preparation of Ruthenium Nanoparticles. Ruthenium nanoparticles were synthesized by the reduction of ruthenium trichloride in presence of reducing agents and stabilizing agents using water as solvent. $\mathrm{RuCl}_{3}$ solution $(0.2 \mathrm{mM})$ was prepared by dissolving the known amount of $\mathrm{RuCl}_{3}$ in $50 \mathrm{~mL}$ distilled water under continuous stirring. Separately, known amount of SDS and $\mathrm{NaBH}_{4}$ was dissolved into $50 \mathrm{~mL}$ distilled water. Molar ratios of $\mathrm{NaBH}_{4} / \mathrm{RuCl}_{3}$ and $\mathrm{SDS} / \mathrm{RuCl}_{3}$ were maintained at 30 and 20, respectively. Colloidal ruthenium nanoparticles were produced by gradual addition of prepared $\mathrm{RuCl}_{3}$ solution into the mixture of $\mathrm{NaBH}_{4}$ and SDS slowly under continuous stirring for $1 \mathrm{~h} \mathrm{[10].}$

2.3. $\mathrm{Ru} / \gamma-\mathrm{Al}_{2} \mathrm{O}_{3}$ Catalyst Preparation. To prepare $\mathrm{Ru} / \gamma$ $\mathrm{Al}_{2} \mathrm{O}_{3}$ catalyst, synthesized colloidal nanoparticles were collected by centrifugation and redispersed into the methanol by sonication (B. Braun Biotech International, Labsonic). $5 \mathrm{gm}$ of $\gamma$-alumina was added in to the solution and the mixture was mechanically stirred at $6500 \mathrm{rpm}$ using Ultraturax (IKA WERKE, GmBH \& Co. KG) for $24 \mathrm{~h}$ at room temperature to form a homogeneous suspension. The mixture was washed with acetone and water to remove the organic material and dried at $100^{\circ} \mathrm{C}$ for $6 \mathrm{~h}$. The Ru supported on $\gamma$-alumina was found in a powder with a dark brown color. The catalyst was

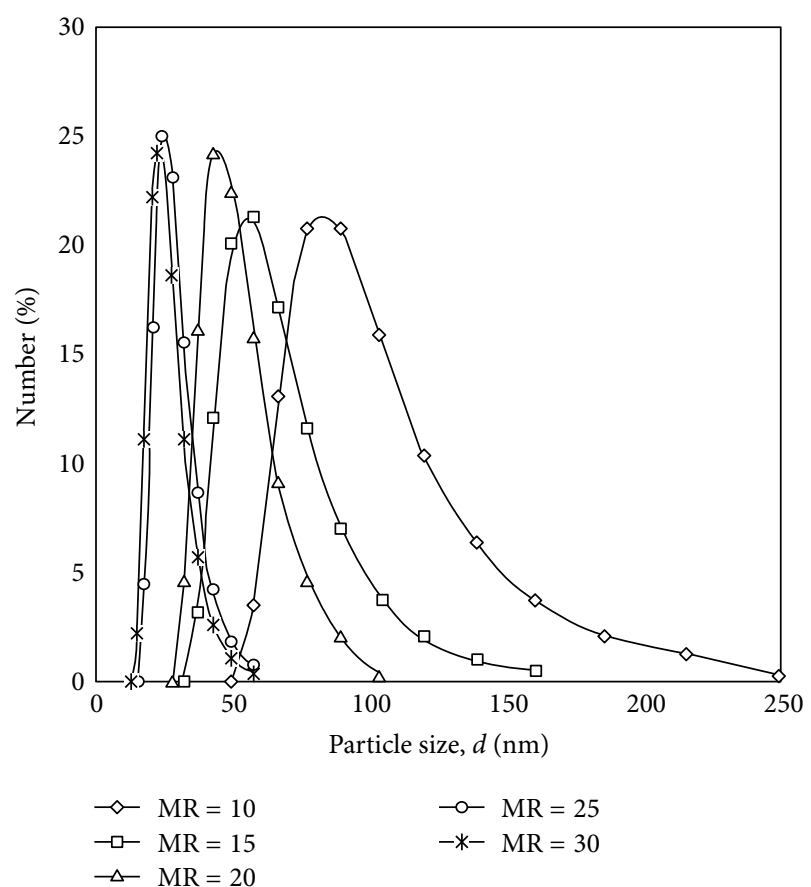

Figure 2: Study of effect of $\mathrm{NaBH}_{4} / \mathrm{RuCl}_{3} \mathrm{MR}$ on particle size using particle-size analyser.

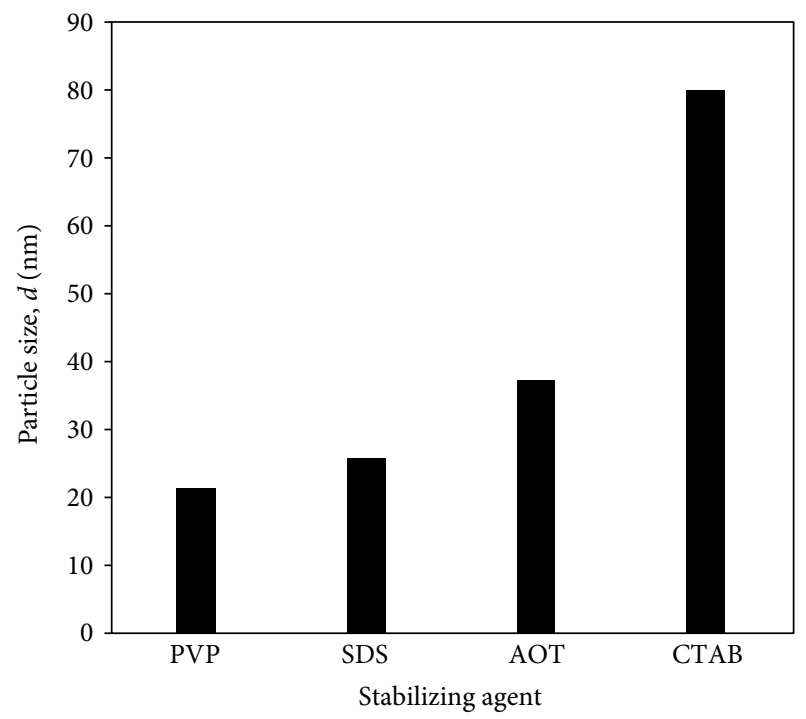

FIgURE 3: Study of effect of different type of stabilizing agents on particle size using particle-size analyser.

calcinated at $300^{\circ} \mathrm{C}$ for $6 \mathrm{~h}$ in an oven. The catalyst was stored in moisture-free atmosphere.

2.4. Characterization. The sizes of nanoparticles were measured using DLS (Malvern Zetasizer, Nano ZS-90, UK). Morphology of the nanoparticles was observed by TEM analysis (Philips Tecnai-20, Holland) operating at $200 \mathrm{kV}$ provides $0.27 \mathrm{~nm}$ point resolution. Nanoparticles stability 

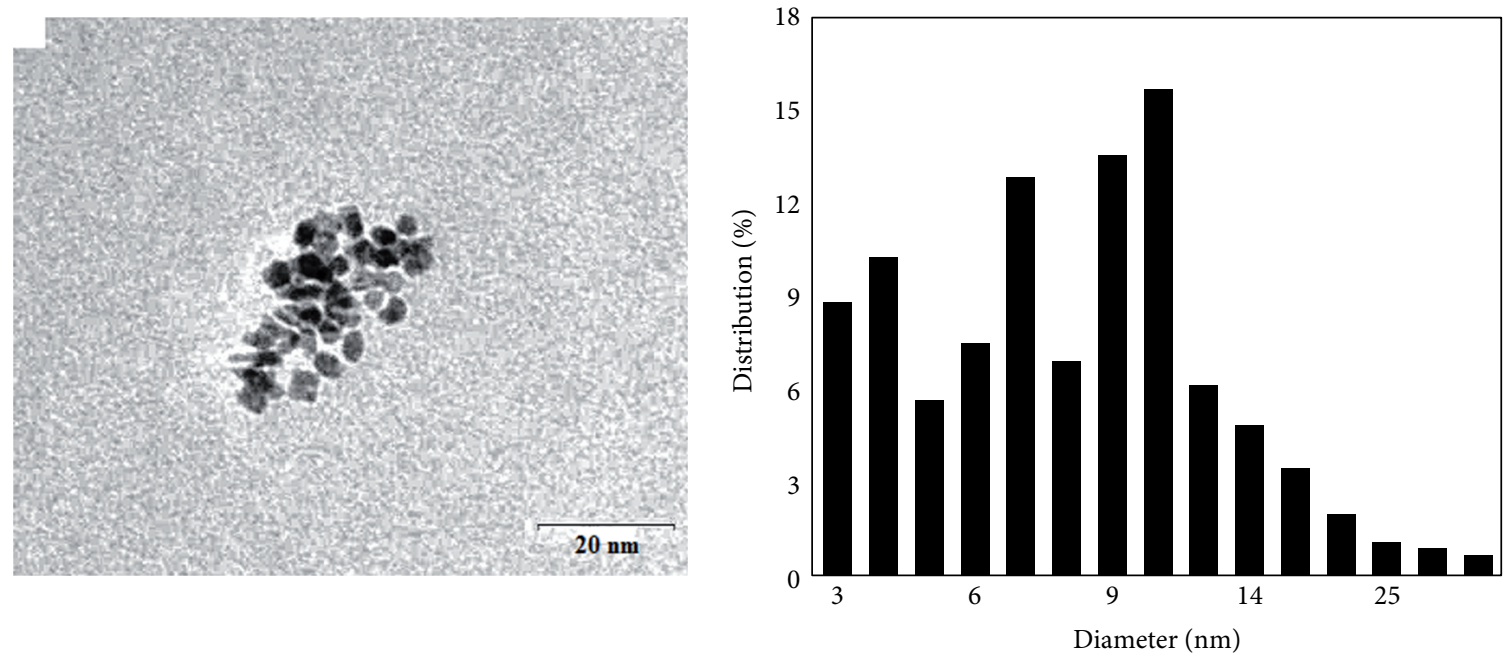

(a)

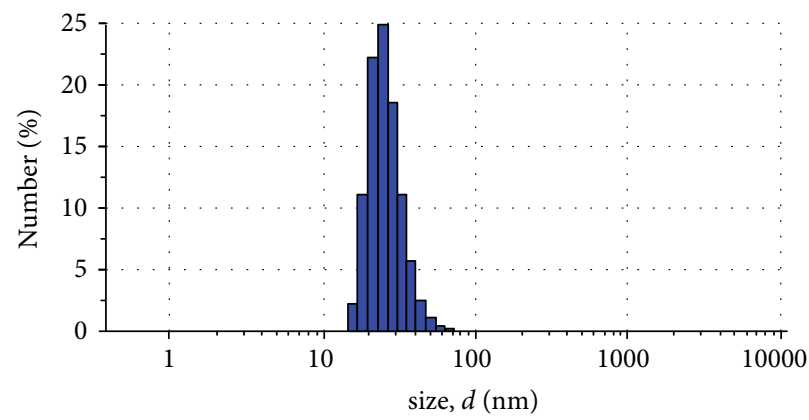

(b)

FIGURE 4: (a) TEM image and number distribution and (b) DLS distribution of Ru nanoparticles using SDS using particle-size analyser.

was analyzed using Turbiscan Classic MA 2000 at light rays of $880 \mathrm{~nm}$ wavelength (Formulaction, France). Phase composition of $\mathrm{Ru} / \gamma-\mathrm{Al}_{2} \mathrm{O}_{3}$ catalyst was observed by X-ray diffraction (Philips, $\mathrm{X}^{\prime}$ Pert-MPD, Holland).

\section{Results and Discussion}

3.1. Effect of $\mathrm{SDS} / \mathrm{RuCl}_{3}$ Molar Ratio. Generally, anionic surfactant, SDS, was used as stabilizer to prevent the growth and aggregation of nanoparticles. $\mathrm{SDS} / \mathrm{RuCl}_{3}$ molar ratio was changed from 1-40 keeping $\mathrm{RuCl}_{3}$ concentration at $0.2 \mathrm{mM}$ and 30 molar ratio (MR) of $\mathrm{NaBH}_{4} / \mathrm{RuCl}_{3}$ (Figure 1). The size of the particles decreased with increasing $\mathrm{MR}$ of $\mathrm{SDS} / \mathrm{RuCl}_{3}$ up to 20 . Hydrodynamic diameter of the colloidal $\mathrm{Ru}$ nanoparticles, which was formed due to aggregation of nanocrystals inside micelles was found to be $90 \mathrm{~nm}$ at $\mathrm{MR}=$ 1 and $20 \mathrm{~nm}$ at $\mathrm{MR}=20$. Above $20 \mathrm{MR}$, size of the particles increased with increasing the $\mathrm{MR}$ of $\mathrm{SDS} / \mathrm{RuCl}_{3}$. Actually larger size of the ruthenium nanoparticles was produced at lower concentration of SDS because of higher rate of agglomeration due to insufficient amount of stabilizing agent in the system [11]. The increase of $\mathrm{SDS} / \mathrm{RuCl}_{3} \mathrm{MR}$, increased the concentration of SDS. High concentration of surfactant increased viscosity, the increase in viscosity led to reduce rate of surfactant migration or reduced rate of diffusion speed of micelles and decreased the electrostatic repulsion, there by promoting the particle agglomeration $[12,13]$.

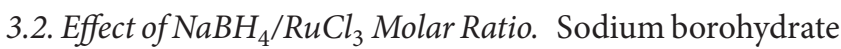
was used as reducing agent for the synthesis of Ru nanoparticles. The effect of $\mathrm{NaBH}_{4}$ concentration was studied by varying $\mathrm{MR}$ of $\mathrm{NaBH}_{4} / \mathrm{RuCl}_{3}$ (10-30), keeping other parameters constant $\mathrm{RuCl}_{3}=0.2 \mathrm{mM}$ and $20 \mathrm{MR}$ of $\mathrm{SDS} / \mathrm{RuCl}_{3}$ (Figure 2).

At lower value of $\mathrm{MR}$ of $\mathrm{NaBH}_{4} / \mathrm{RuCl}_{3}(\mathrm{MR}=10)$, larger size of nanoparticles was observed by DLS due to the insufficient reduction of $\mathrm{RuCl}_{3}$. However, with increasing the MR of $\mathrm{NaBH}_{4} / \mathrm{RuCl}_{3}$ from 15 to 30, narrow peaks were obtained, suggesting that Ru nanoparticles were produced with smaller size. Liu et al. [14] also found that lower concentration of $\mathrm{NaBH}_{4}$ produced boron hydroxide through hydrolysis of $\mathrm{NaBH}_{4}$. This boron hydroxide was absorbed to the $\mathrm{Ru}$ nanoparticles, reducing the electron density of surface and causing aggregation of Ru nanoparticles which resulted larger nanoparticles size. On the other hand, higher concentration of $\mathrm{NaBH}_{4}$ increased the concentration of boron hydroxide 


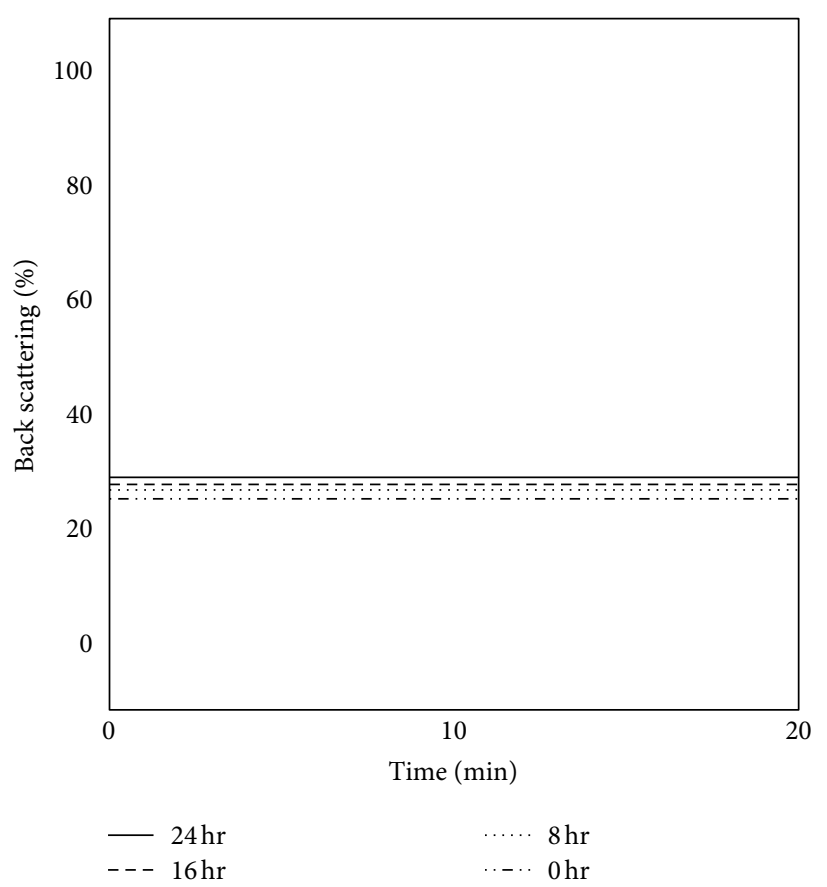

(a)

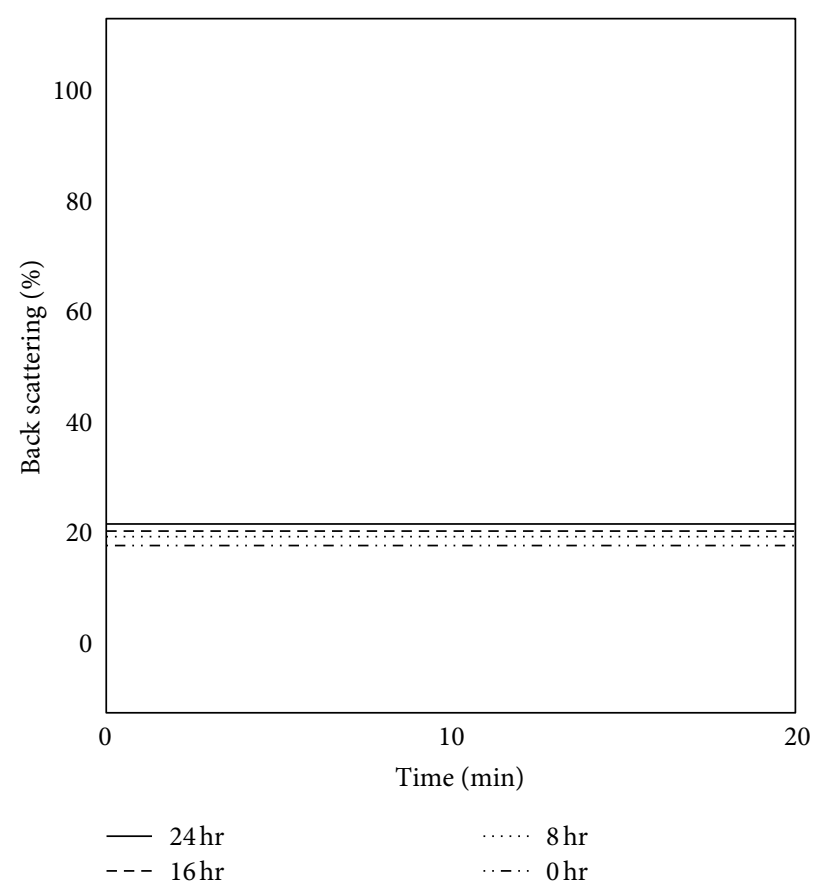

(b)

FIgURE 5: Study of stability of Ru nanoparticles at different stabilizing agents, (a) SDS and (b) PVP, using Turbiscan.

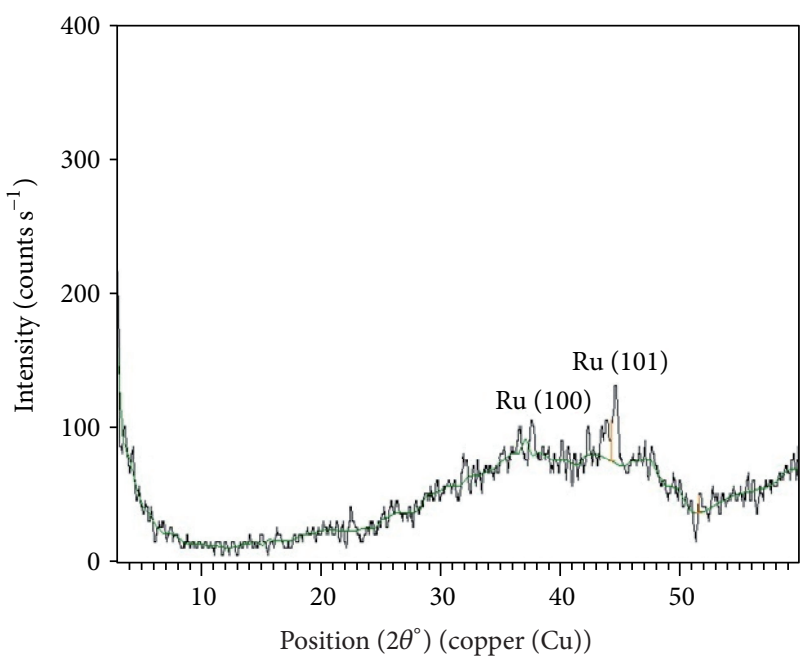

FIGURE 6: XRD of $\mathrm{Ru} / \gamma-\mathrm{Al}_{2} \mathrm{O}_{3}$ supported catalyst.

which formed thick $\mathrm{BH}_{4}^{-}$layer preventing the boron hydroxide from absorbing into the surface of $\mathrm{Ru}$ nanoparticles, resulting in well-dispersed smaller nanoparticles.

3.3. Effect of Different Types of Stabilizing Agents on Particles Size. In order to know the effect of different types of stabilizing agent like PVP, SDS, CTAB, and AOT on the size of Ru nanoparticles, at constant $\left(\mathrm{RuCl}_{3}\right)=0.2 \mathrm{mM}, 20$ MR of Surfactant $/ \mathrm{RuCl}_{3}$ and $30 \mathrm{MR}$ of $\mathrm{NaBH}_{4} / \mathrm{RuCl}_{3}$. It was observed that the smallest particle size (Figure 3) was

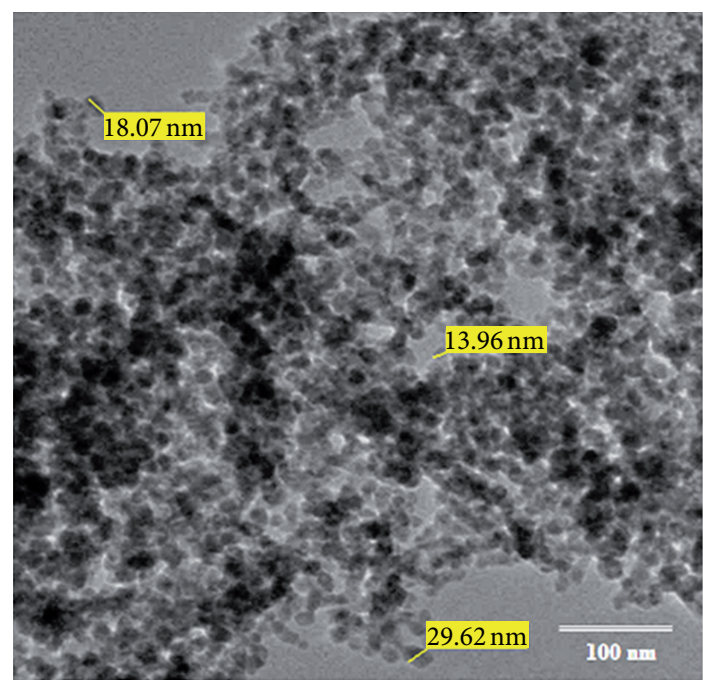

FIGURE 7: TEM image of $\mathrm{Ru} / \gamma-\mathrm{Al}_{2} \mathrm{O}_{3}$-supported catalyst.

obtained for PVP $(20 \mathrm{~nm})$ and SDS $(25 \mathrm{~nm})$ and the particle size was significantly smaller than AOT and CTAB. Actually PVP would act as stabilizing as well as a reducing agent, which resulted in the lowest particle size of ruthenium. For cationic surfactant $(\mathrm{CTAB}), \mathrm{Ru}$ nanoparticles were attracted by the positive charge of the surfactant, hence agglomerated near the outside of micelle which resulted larger nanoparticles $[15,16]$.

TEM image and DLS histogram of SDS stabilized colloidal Ru nanoparticles were shown in Figure 4. TEM showed 
that average particle size was 3-25 nm, lower than that of the particle size (20-70 nm) obtained by DLS. Actually in TEM only nanoparticles without surfactant layers were visible, this resulted lower in particle size.

3.4. Stability of Ruthenium Nanoparticles. The nanoparticles were stabilized due to attractive and repulsive electrostatic forces created by stabilizing agents present in the system. Nanoparticles stability was analyzed using transmission and back scattering (BS) profiles, scanning the colloidal sample by light rays of $880 \mathrm{~nm}$ wavelength using Turbiscan. It was observed that BS profiles at different times for SDS and PVP at $20 \mathrm{MR}$ (Figure 5) were superimposing which indicated that the structure and average size of the Ru nanoparticles were not changing up to $24 \mathrm{~h}$.

3.5. Characterization of $\mathrm{Ru} / \gamma-\mathrm{Al}_{2} \mathrm{O}_{3}$ Catalyst. XRD diagram (Figure 6) showed that the diffraction peak at $2 \theta=44.5^{\circ}$, which was exactly consistent with the $d$ value $(2.07 \AA)$ of ruthenium metal [16]. The size of the Ru cluster was calculated by the Debye Scherrer formula [17] which was found to be $15 \mathrm{~nm}$, nearly close to the average diameter observed by TEM analysis of $\mathrm{Ru} / \gamma-\mathrm{Al}_{2} \mathrm{O}_{3}$ catalyst as shown in Figure 7.

\section{Conclusion}

SDS-stabilized ruthenium nanoparticles were synthesized by proper selection of stabilizer, reducing agent and optimizing $\mathrm{SDS} / \mathrm{RuCl}_{3} \mathrm{MR}$ at 20, $\mathrm{NaBH}_{4} / \mathrm{RuCl}_{3} \mathrm{MR}$ at 30. Stabilized ruthenium nanoparticles were dispersed on $\gamma$-alumina by mechanical stirring to obtain uniformly distributed supported catalyst. The size of the nanoparticles obtained from XRD was consistent with TEM data.

\section{References}

[1] T. Teranish and M. Miyake, "Size control of palladium nanoparticles and their crystal structures," Chemistry of Materials, vol. 10, no. 2, pp. 594-600, 1998.

[2] T. Tsukatani and H. Fujihara, "New method for facile synthesis of amphiphilic thiol-stabilized ruthenium nanoparticles and their redox-active ruthenium nanocomposite," Langmuir, vol. 21, no. 26, pp. 12093-12095, 2005.

[3] F. Bonet, C. Guéry, D. Guyomard, R. Herrera Urbina, K. TekaiaElhsissen, and J. M. Tarascon, "Electrochemical reduction of noble metal compounds in ethylene glycol," International Journal of Inorganic Materials, vol. 1, no. 1, pp. 47-51, 1999.

[4] Y. Wang, J. Ren, K. Deng, L. Gui, and Y. Tang, "Preparation of tractable platinum, rhodium, and ruthenium nanoclusters with small particle size in organic media," Chemistry of Materials, vol. 12, no. 6, pp. 1622-1627, 2000.

[5] X. Yan, H. Liu, and K. Y. Liew, "Size control of polymerstabilized ruthenium nanoparticles by polyol reduction," Journal of Materials Chemistry, vol. 11, no. 12, pp. 3387-3391, 2001.

[6] H. Li, R. Wang, Q. Hong et al., "Ultrasound-assisted polyol method for the preparation of SBA-15-supported ruthenium nanoparticles and the study of their catalytic activity on the partial oxidation of methane," Langmuir, vol. 20, no. 19, pp. 8352-8356, 2004.

[7] F. Maillard, G. Q. Lu, A. Wieckowski, and U. Stimming, "Rudecorated Pt surfaces as model fuel cell electrocatalysts for CO electrooxidation," Journal of Physical Chemistry B, vol. 109, no. 34, pp. 16230-16243, 2005.

[8] K. S. Chou, Y. C. Lu, and H. H. Lee, "Effect of alkaline ion on the mechanism and kinetics of chemical reduction of silver," Materials Chemistry and Physics, vol. 94, no. 2-3, pp. 429-433, 2005.

[9] K. D. Kim, D. N. Han, and H. T. Kim, "Optimization of experimental conditions based on the Taguchi robust design for the formation of nano-sized silver particles by chemical reduction method," Chemical Engineering Journal, vol. 104, no. 1-3, pp. 55-61, 2004.

[10] K. C. Song, S. M. Lee, T. S. Park, and B. S. Lee, "Preparation of colloidal silver nanoparticles by chemical reduction method," Korean Journal of Chemical Engineering, vol. 26, no. 1, pp. 153-155, 2009.

[11] Y. Liguo and Z. Yanhum, "Preparation of nano-silver flake by chemical reduction method," Rare Metal Materials and Engineering, vol. 39, no. 3, pp. 401-404, 2010.

[12] R. Patakfalvi, S. Papps, and I. Dekany, "The kinetics of homogeneous nucleation of silver nanoparticles stabilized by polymers," Journal of Nanoparticle Research, vol. 9, no. 3, pp. 353-364, 2007.

[13] R. Pataklvi, Z. Viranyi, and I. Dekany, "Kinetics of silver nanoparticle growth in aqueous polymer solutions," Colloid \& Polymer Science, vol. 283, pp. 299-305, 2004.

[14] J. Liu, J. B. Lee, D. H. Kim, and Y. Kim, "Preparation of high concentration of silver colloidal nanoparticles in layered laponite sol," Colloids and Surfaces A, vol. 302, no. 1-3, pp. 276-279, 2007.

[15] S. U. Nandanwar, M. Chakraborty, S. Mukhopadhyay, and K. T. Shenoy, "Stability of ruthenium nanoparticles synthesized by solvothermal method," Crystal Research and Technology, vol. 46, no. 4, pp. 321-420, 2006.

[16] X. Yan, H. Liu, and K. Y. Liew, "Size control of polymerstabilized ruthenium nanoparticles by polyol reduction," Journal of Materials Chemistry, vol. 11, no. 12, pp. 3387-3391, 2011.

[17] E. Godocikova, P. Balaz, E. Gock, W. Choi, and B. Kim, "Mechanochemical synthesis of the nanocrystalline semiconductors in an industrial mill ," Powder Technology, vol. 164, no. 3, pp. 147-152, 2006. 

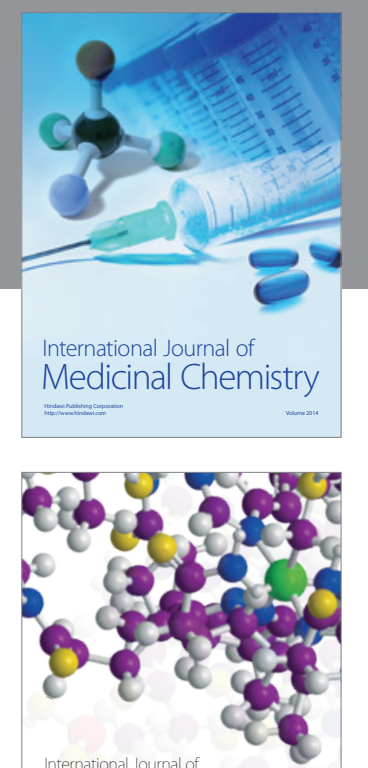

\section{Carbohydrate} Chemistry

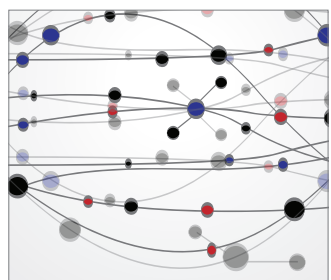

The Scientific World Journal
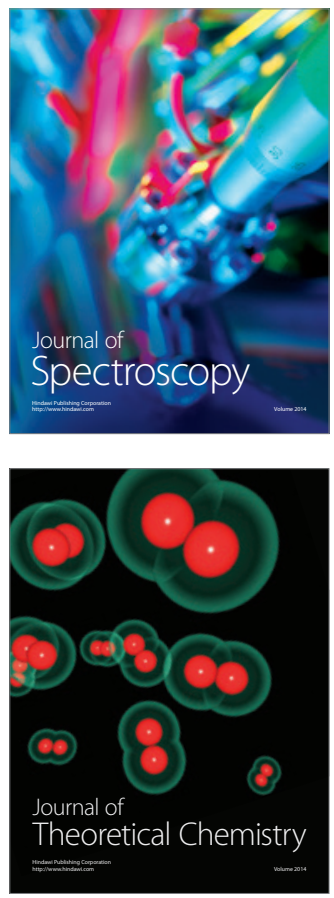
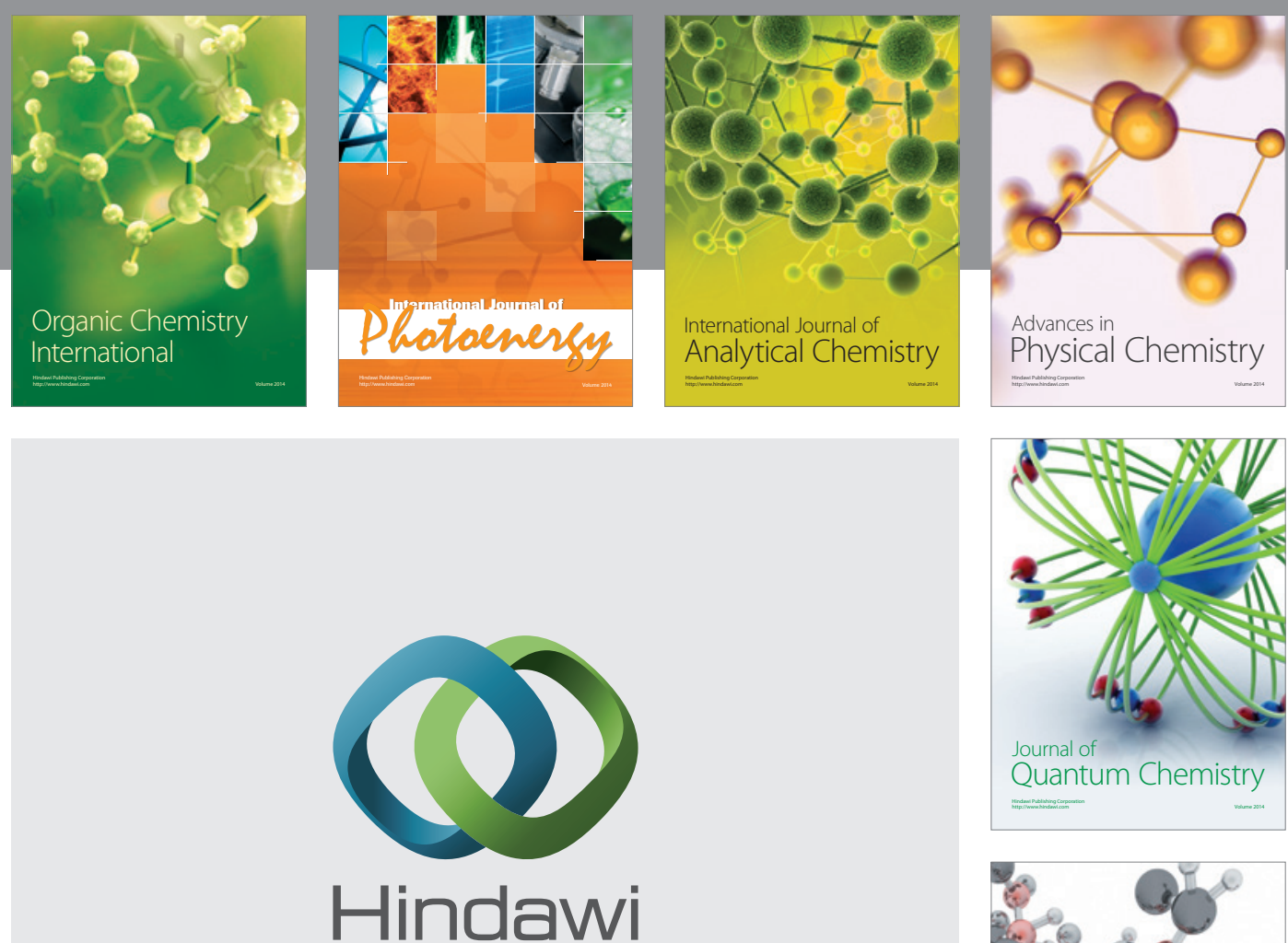

Submit your manuscripts at

http://www.hindawi.com

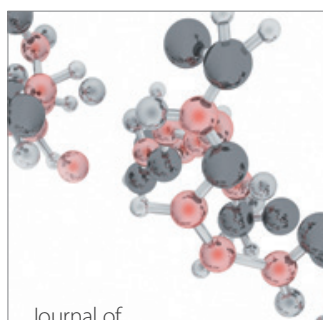

Analytical Methods

in Chemistry

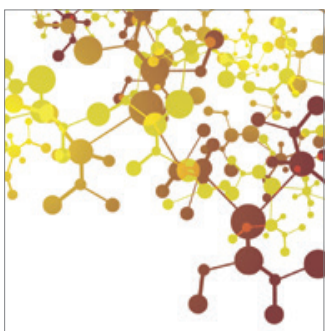

Journal of

Applied Chemistry

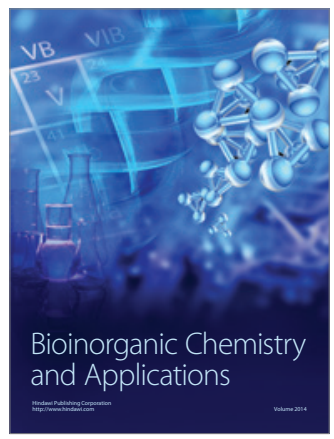

Inorganic Chemistry
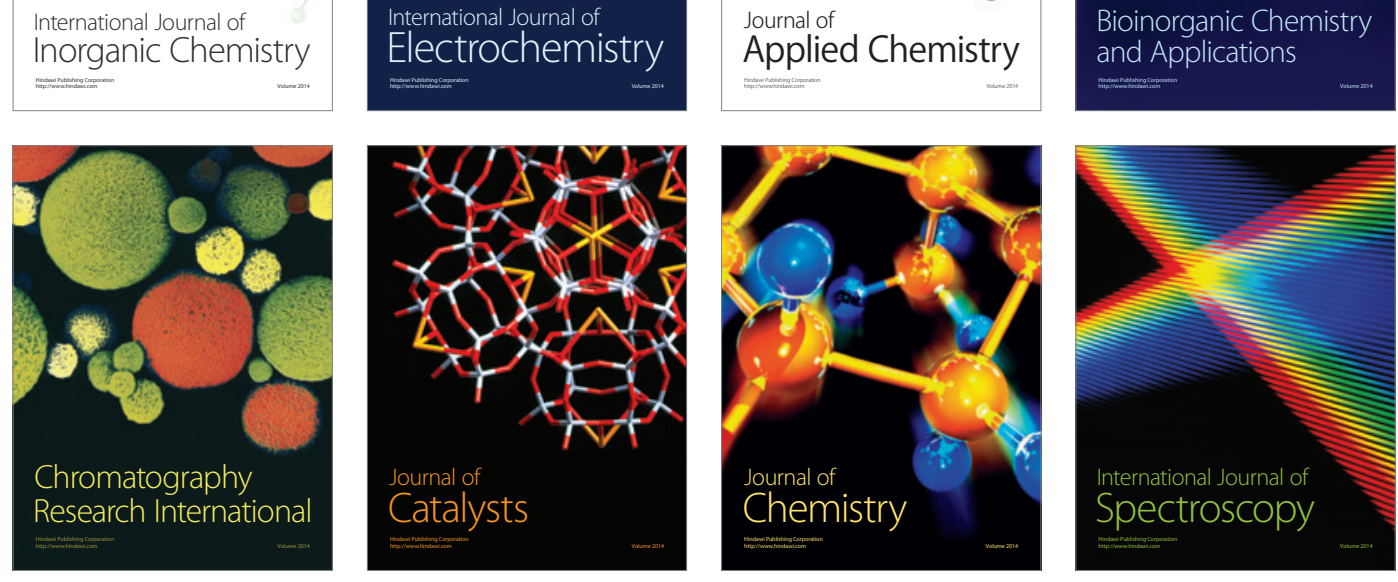